\title{
Research on Stratified Cluster Evaluation of Enterprise Green Technology Innovation Based on the Rough Set
}

\author{
Jianmin Xie, Xiaowo Tang, Yunfei Shao \\ School of Economic and Management, University of Electronic Science and Technology of China, Chengdu, China \\ Email: xiejianmin@swust.edu.cn
}

Received January 15, 2012; revised February 14, 2012; accepted February 21, 2012

\begin{abstract}
This paper analyzes the impact of corporate green technological innovation which is based on internal and external environmental factors, using hierarchical clustering approach to building a multi-index system. Evaluation index system for the various environmental factors inherent in the ambiguity, the use of rough set theory set a new business model for green technology innovation and environmental assessment. The model overcomes the traditional rough set model calculation bottleneck. Empirical studies demonstrate that the proposed index system and evaluation model have effectiveness, relevance and objectivity.
\end{abstract}

Keywords: Green Technology Innovation; Innovation Environment; Index System; Rough Set

\section{Introduction}

In recent years the human facing many development problems, such as the environmental pollution, the abnormal climate change, the insufficient supply of resources and so on. This problem is not only restricting development of economic and social sustainable, but also endangering the human beings survival and development. To face with the deepening green consumer spending outlook, companies must change the extensive production and management of the high consumption, low efficiency and heavy pollution into the low-cost, high efficiency, less pollution-intensive production methods, that can be improve resource efficiency and production efficiency. The key to achieve this transformation is the implementation of green technology innovation. To successful implement the green technology innovation, companies needed a good environment, the objective evaluation of internal and external environment, which will help companies, find and create a good environment for green innovation [1].

The green technology innovation is the general definition of technology, process and product innovation which must follow eco-economy principles and laws of ecology, conserve resources and energy, and avoid, eliminate or reduce environmental pollution and ecological damage. Academics have been studied on the green technical innovation from different angles. Vicki Norberg-Bohm (1999) discussed how to design public policy mechanisms to promote the hinder innovation in pollution control technology, and set up six policy design standards to promote the green technology innovation [2]. Yushan Chen (2006) explored the business green innovation for a positive impact on the performance of its competitive advantage. The study found that the development of enterprises can be strengthened by the green technology innovation; businesses should recognize the value of green innovation and the correct positioning [3]. Yushan Chen (2008) also verified the core capabilities and the image of green innovation and environmental performance was positively correlated, and confirmed the development of enterprises can be enhanced by the image of green innovation building, the green core competencies investment [4].

It is a late start of China's green technology innovation. In recent years, China primarily focused on the meaning of green innovation and green technology innovation barriers and countermeasures research. In the terms of green technology innovation Meaning, Ping Li (2001) compared the green technology innovation with the traditional technological innovation. As a result, he pointed out that technological innovation from the traditional into the green is the only way to achieve sustainable development [5]. Ling Yuan (2000) described the content and development Status of the green technology and green technology innovation, it has been defined the concept of green technology innovation from the economic point of view [6]. In research for the enterprise level, Huafeng Yang (2005) explored the enterprise to promote green technology innovation barriers, made for the circular economy to carry out business strategies and innovative green technology [7]. Jun Jiao (2011) analyzed the green 
value network which consisted with the business and stakeholders, proposed the basic theoretical framework which based on the relationship between the green strategic alliance and the green innovation, and elaborated on the elements of green technology innovation and operational mechanisms [8]. Through the investigation and empirical research, Qinghua Zhu (2011) proposed the Chinese telecommunications equipment manufacturing industry to implement eco-design practice dynamic model, the results showed that: the external power for telecom equipment manufacturers had a positive effect on ecodesign practice [9].

Looking at the domestic and foreign innovation in green technology research, the academia made some research on the practical aspects and its content, but there were few researches on internal and external business environment in green technology innovation. To evaluate the Green technology innovation in the enterprise, the fuzzy comprehensive evaluation method was mostly used [10]. This method required pre-built membership functions, the build process more relied on experience, which also affected the objectivity of the environmental assessment. In-depth analysis of enterprise green technical innovation and external environmental influences, the new evaluation model is established by using the rough set theory [11], as to the internal and external environment of uncertainty, building a hierarchical clustering enterprise evaluation index system. Rough sets are different from the AHP [12], fuzzy sets [13] and the evidence theory based on probability [14], and it does not need the pro- bability distribution of membership functions such as prior knowledge, so the innovation in green technology is more objective evaluation of the environment. Finally, through the empirical research, this paper verifies the validity of index system and evaluation model.

\section{The Enterprise Evaluation Index System of Green Technology Innovation}

The innovation environment was a key factor to determine whether the green technology innovation can be success or not, to impact and restrict the quality of the of the green technology innovation business activities. The business green technology innovation environment was composed of the people who impacted the green technology innovation, organizations and other elements. The business green technology innovation environment changed the new technology into the network systems which could promote the business green power by the mutual cooperation of Various actors and role [15]. This paper analyzes the impact of two levels of innovation in green technology enterprise environmental factors from internal environment and external environment, using hierarchical clustering approach to building enterprise green technical innovation evaluation system shown in Table 1.

\section{Evaluation Model}

\subsection{Model Related Definition}

A decision system $M$ can be formally expressed as

Table 1. The enterprise evaluation index system of green technology innovation.

\begin{tabular}{|c|c|c|c|}
\hline & & & Green environmental awareness $e_{111}$ \\
\hline & & External cultural environment $e_{11}$ & Green technology competition $e_{112}$ \\
\hline & & & Green consumption of consumer $e_{113}$ \\
\hline & & & Financial support policies $e_{121}$ \\
\hline & Internal environment $e_{1}$ & Policy institutional environment $e_{12}$ & The complete extent of laws and regulations $e_{122}$ \\
\hline & & & Financial and tax incentives $e_{123}$ \\
\hline & & & Human resources $e_{131}$ \\
\hline & & External resources environment $e_{13}$ & Technical resources $e_{132}$ \\
\hline \multirow{9}{*}{$\begin{array}{l}\text { The enterprise evaluation } \\
\text { index system of green } \\
\text { technology innovation }\end{array}$} & \multirow{9}{*}{ External environment $e_{2}$} & \multirow[b]{3}{*}{ Internal cultural environment $e_{21}$} & Financing difficulty $e_{133}$ \\
\hline & & & Management emphasis $e_{211}$ \\
\hline & & & Green conception $e_{212}$ \\
\hline & & \multirow{3}{*}{ Internal institutional environment $e_{22}$} & Incentives $e_{221}$ \\
\hline & & & Intellectual property protection $e_{222}$ \\
\hline & & & Cooperative research and development mechanism $e_{223}$ \\
\hline & & \multirow{3}{*}{ Internal resources environment $e_{23}$} & Innovative talent pool $e_{231}$ \\
\hline & & & Green technology innovation R \& D funds $e_{232}$ \\
\hline & & & The level of equipment and process improvement $e_{233}$ \\
\hline
\end{tabular}


quaternion:

$$
M=\left(U, A t,\left\{V_{a} \mid a \in A t\right\},\left\{I_{a} \mid a \in A_{\tau}\right\}\right)
$$

$U$ is a finite non-empty collection of objects, also known as the domain, $A$ is a finite non-empty set of attributes. $V_{a}$ indicates that the property $a \in A_{t}$, the range of attribute values, that attribute $a$ of the range,

$I_{a}: U \rightarrow V_{a}$ is an information function. If $A \subseteq A_{\tau}$, then $I_{a}(x)$ shows the object $x$ of property value on property $A$.

Write $\phi$ as a formula for decision-making $M$, and the set $m(\phi)=\left\{x \in U, x \mid=_{M} \phi\right\}$ as the meaning of $\phi$ in $M$. The argument of $m(\phi)$ is formula Language, which value is a subset of a collection of objects in information sheet. $m(\phi)$ is the object of all which has the character of formula $\phi$.

Using $\mathcal{L}(A)$ indicates the language which was defined by attribute subset $A$. Considering the attribute subset $A \subseteq A t$ and the corresponding language $X$, it can be defined the set of formal definitions are as follows.

Definition 1: In decision-making system $M$, only if there is a formula $\phi$ in the language $\mathcal{L}(A)$ allows $X=m(\phi)$, the sub-set $X \subseteq U$ can be defined by the attributed subset $A \subseteq A t$, Otherwise, it was not defined. Definable set of all expressed as:

$$
\operatorname{Def}(U, \mathcal{L}(A))=\{m(\phi) \mid \phi \in \mathscr{L}(A)\}
$$

Definition 2: If the two objects in the language $\mathcal{L}(A)$ described by the same formula, or their individual property values on $A$ are the same, claiming that the two objects are equivalent.

Definition 3: Let $E(A)$ be an equivalence relation on $M, X \subseteq U$, the upper and lower approximation operators $\overline{\operatorname{apr}}_{E(A)}, \underline{\operatorname{apr}}_{E(A)}$ is defined as:

$$
\begin{aligned}
\overline{\operatorname{apr}}(X) & =\bigcup\{Y \mid Y \in \sigma(U / E(A)), Y \cap X \neq \phi\} \\
& =\bigcap\{Y \mid Y \in \operatorname{Def}(U, \mathcal{L}(A)), X \subseteq Y\} ; \\
\underline{\operatorname{apr}(X)} & =\bigcup\{Y \mid Y \in \sigma(U / E(A)), Y \subseteq X\} \\
& =\bigcup\{Y \mid Y \in \operatorname{Def}(U, \mathcal{L}(A)), Y \subseteq X\} .
\end{aligned}
$$

On the approximation of $\overline{\operatorname{apr}}(X)$ is the least definable set containing $X, \operatorname{apr}(X)$ is included under the approximation of the maximum can be defined in the $X$ set.

Definition 4: Consider the subset $X \subseteq U$, the domain space will be divided into three areas:

1) Positive region of set $X: \operatorname{POS}(X)=\operatorname{apr}(X)$;

2) Negative region of set $X$ :

$\operatorname{NEG}(X)=\operatorname{POS}(\sim X)=U-\overline{\operatorname{apr}}(X)$;

3) Boundary region of set $X$ :

$$
B N D(X)=\overline{\operatorname{apr}}(X)-\underline{\operatorname{apr}}(X) \text {. }
$$

If $B N D(X)$ is the empty set, we called set $X$ about relationship $E(A)$ is clear (crisp); the other hand, if $B N D(X)$ is not an empty set, we called set $X$ about relationship $E(A)$ is rough.

\subsection{Model}

Supposed $E$ as the to be evaluated environmental factors, if there are number $n$ factors in the $l$ layer, then the environmental factors can be expressed as:

$E_{l}=\left[E_{l 1}, E_{l 2}, \cdots, E_{l n}\right]$, the evaluation satisfaction of environmental factors was expressed by $E S$. To construct a definition of rough set decision as table $M$. To constitute the object of different combinations of demand for $U, E$ indicated condition attributes, ES indicated decision attribute. The investigated results of the related personnel is the attribute values, the environmental factors attributes set which to be evaluated was expressed by $A$, the survey satisfaction attribute set was expressed by $B$.

By calculating the area $A$ is whether equal to $B$ to determine the environmental factors can reduce or not. If $\operatorname{POS}_{A}(B)=\operatorname{POS}(B)$, this shows that $E S$ relative to $E_{i}$ can be reduced .If not, then it is on the contrary.

Using $\lambda_{l i}^{\prime}$ indicated the same node evaluation results in $l$ layer with the environmental factor $E_{l i}$ which was located in layer $l$ number $i$. The green environment for technology innovation evaluation model can be expressed as

$$
\lambda_{l i}^{\prime}=\frac{\left|\operatorname{POS}_{A}(B)\right|}{|U|}-\frac{\underset{A-\left\{E_{l i}\right\}}{\operatorname{POS}(B)}}{|U|}
$$

Using $\lambda_{i j}$ indicated the evaluation results of the environmental factor $E_{l i}$ which was located in layer $l$ number $i$, then $\lambda_{i j}$ was equal to $\lambda_{i j}$ which multiplied with the evaluation results of all the parent nodes in this environmental factor.

\section{Empirical Research}

As an enterprise for the study which selected 20 employees of the enterprise survey who involved in management, technology development and front-line workers.

According to the evaluation index system proposed by the above, the first layer of environmental factors to be evaluated of the enterprise external environment $E_{1}=$ [external cultural environment $\left(E_{11}\right)$, policies and systems environment $E_{12}$, external resources and environment $\left.\left(E_{13}\right)\right]$. Using 1,3 and 5 indicated the staff satisfaction with the environment which was to be evaluated. The decision table which constituted with the survey results about the first layer was shown in Table 2. 
The relative positive domain which calculated according to Table 1 determined the various external environ- mental factors in relation to employee satisfaction whether reduction in the first layer.

The relative positive region $E_{11}$ is:

$$
\underset{A-\left\{E_{11}\right\}}{\operatorname{POS}(B)_{A}}=\left\{\left\{U_{1}, U_{10}\right\},\left\{U_{3}, U_{12}\right\},\left\{U_{4}, U_{13}\right\},\left\{U_{5}, U_{14}\right\},\left\{U_{6}, U_{15}\right\},\left\{U_{9}, U_{18}\right\}\left\{U_{7}, U_{16}, U_{25}\right\},\left\{U_{8}, U_{17}\right\},\left\{U_{11}, U_{20}\right\}\right\}
$$

The relative positive region $E_{12}$ is:

$$
\begin{aligned}
& \underset{A-\left\{E_{12}\right\}}{\operatorname{POS}(B)_{A}=}\left\{\left\{\left\{U_{1}, U_{4}\right\},\left\{U_{3}, U_{6}, U_{9}\right\},\left\{U_{5}, U_{8}\right\},\left\{U_{10}, U_{13}\right\},\left\{U_{23}, U_{26}\right\},\left\{U_{11}, U_{14}, U_{17}\right\},\left\{U_{12}, U_{15}, U_{18}\right\},\right.\right. \\
&\left.\left\{U_{19}, U_{22}, U_{25}\right\},\left\{U_{21}, U_{24}, U_{27}\right\}\right\}
\end{aligned}
$$

The relative positive region $E_{13}$ is:

$$
\underset{A-\left\{E_{13}\right\}}{\operatorname{POS}(B)_{A}}=\left\{\left\{U_{1}, U_{2}\right\},\left\{U_{5}, U_{6}\right\},\left\{U_{7}, U_{8}, U_{9}\right\},\left\{U_{11}, U_{12}\right\},\left\{U_{14}, U_{15}\right\},\left\{U_{16}, U_{17}, U_{18}\right\},\left\{U_{19}, U_{20}\right\},\left\{U_{23}, U_{24}\right\},\left\{U_{26}, U_{27}\right\}\right\}
$$

$$
\begin{aligned}
& \text { Because } \operatorname{POS}_{A}(B) \neq \underset{A-\left\{E_{11}\right\}}{\operatorname{POS}(B)_{A} ;} \\
& \operatorname{POS}_{A}(B) \neq \underset{A-\left\{E_{12}\right\}}{\operatorname{POS}(B)_{A} ;} ; \operatorname{POS}_{A}(B) \neq \underset{A-\left\{E_{13}\right\}}{\operatorname{POS}(B)_{A}} \text {, the }
\end{aligned}
$$

external environment $E_{11}, E_{12}, E_{13}$ in the first layer of the enterprises green technology innovation as to the satisfaction ES can not reduce. It also means that the three factors in the first external environment layer can not be ignored.

It can be calculated the first layer external environment evaluation results by the Formula (5).

The evaluation results of $E_{11}, E_{12}$ and $E_{13}$ is:

$$
\begin{aligned}
& \lambda_{11}^{\prime}=\frac{\left|\operatorname{POS}_{A}(B)\right|}{|U|}-\frac{\begin{array}{c}
P O S(B) \\
A-\left\{E_{11 A}\right\}
\end{array}}{|U|}=1-\frac{19}{27}=0.296 \\
& \lambda_{12}^{\prime}=\frac{\left|P_{A}(B)\right|}{|U|}-\frac{\begin{array}{c}
P O S(B) \\
A-\left\{E_{12 A}\right\}
\end{array}}{|U|}=1-\frac{23}{27}=0.148
\end{aligned}
$$

$$
\lambda_{13}^{\prime}=\frac{\left|\operatorname{POS}_{A}(B)\right|}{|U|}-\frac{\begin{array}{c}
P O S(B) \\
A-\left\{E_{13 A}\right\}
\end{array}}{|U|}=1-\frac{20}{27}=0.259
$$

According to the calculation results can be seen: $\lambda_{11}^{\prime}>\lambda_{13}^{\prime}>\lambda_{12}^{\prime}$.

Using the same method to calculate the internal evaluation results of the business green technology innovation environment.The first layer of environmental factors to be evaluated of the enterprise internal environment $E_{1}=$ [internal cultural environment $\left(E_{21}\right)$, internal institutional environment $\left(E_{22}\right)$, internal resources environment $\left.\left(E_{23}\right)\right]$. The decision table which constituted with the survey results about the second layer was shown in Table 3.

The relative positive domain which calculated according to Table 3 determined the various internal environmental factors in relation to employee satisfaction whether reduction in the first layer.

The relative positive region $E_{21}$ is:

$$
\underset{A-\left\{E_{21}\right\}}{\operatorname{POS}(B)_{A}}=\left\{\left\{U_{1}, U_{10}\right\},\left\{U_{2}, U_{11}\right\},\left\{U_{3}, U_{12}\right\},\left\{U_{6}, U_{15}\right\},\left\{U_{7}, U_{16}\right\},\left\{U_{8}, U_{17}\right\},\left\{U_{18}, U_{27}\right\}\right\} .
$$

The relative positive region $E_{22}$ is:

$$
\underset{A-\left\{E_{22}\right\}}{\operatorname{POS}(B)}=\left\{\left\{U_{1}, U_{4}\right\},\left\{U_{2}, U_{5}\right\},\left\{U_{6}, U_{9}\right\},\left\{U_{13}, U_{16}\right\},\left\{U_{14}, U_{17}\right\},\left\{U_{22}, U_{25}\right\},\left\{U_{23}, U_{26}\right\},\left\{U_{24}, U_{27}\right\}\right\} .
$$

The relative positive region $E_{23}$ is:

$$
\begin{aligned}
& \underset{A-\left\{E_{23}\right\}}{\operatorname{POS}(B)_{A}=}\left\{\left\{\left\{U_{1}, U_{2}, U_{3}\right\},\left\{U_{4}, U_{5}\right\},\left\{U_{7}, U_{8}, U_{9}\right\},\left\{U_{10}, U_{11}, U_{12}\right\},\left\{U_{16}, U_{17}\right\},\left\{U_{13}, U_{14}, U_{15}\right\},\left\{U_{19}, U_{20}, U_{21}\right\},\right.\right. \\
&\left.\left\{U_{22}, U_{23}, U_{24}\right\},\left\{U_{25}, U_{26}, U_{27}\right\}\right\} .
\end{aligned}
$$

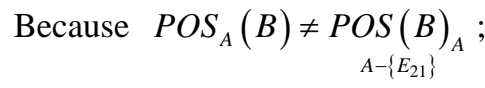

$$
\operatorname{POS}_{A}(B) \neq \underset{A-\left\{E_{22}\right\}}{\operatorname{POS}(B)_{A}} ; \quad \operatorname{POS}_{A}(B) \neq \underset{A-\left\{E_{23}\right\}}{\operatorname{POS}(B)_{A}} \text {, the }
$$

internal environment $E_{21}, E_{22}$ and $E_{23}$ in the first layer of the enterprises green technology innovation as to the satisfaction ES can not reduce. It also means that the three factors in the first internal environment layer can not be ignored.

It can be calculated the first layer internal environment evaluation results by the formula (5).

The evaluation results $E_{21}, E_{22}$ and $E_{23}$ is: 


$$
\begin{aligned}
& \lambda_{21}^{\prime}=\frac{\left|P_{A}(B)\right|}{|U|}-\frac{P O S(B)}{|U|}=1-\frac{14}{27}=0.481 \\
& \lambda_{22}^{\prime}=\frac{\left|P O E_{21}(B)\right|}{|U|}-\frac{\begin{array}{c}
P O S(B) \\
A-\left\{E_{22}\right\}
\end{array}}{|U|}=1-\frac{16}{27}=0.407 \\
& \lambda_{23}^{\prime}=\frac{\left|P O S_{A}(B)\right|}{|U|}-\frac{\begin{array}{c}
P O S(B) \\
A-\left\{E_{23}\right\}
\end{array}}{|U|}=1-\frac{25}{27}=0.074
\end{aligned}
$$

The final evaluation result was calculated by the survey of 20 employees that was shown in Table 4.

The weight of the first layer environmental indicators set by the evaluation team. Let the set of weights is $m=\left\{m_{1}, m_{2}, m_{3}, m_{4}, m_{5}, m_{6}\right\}$. Value of each weight is: $m_{1}=1, m_{2}=2, m_{3}=3, m_{4}=4$. Corresponding set of weights is $m=$ \{Not important, general important,

Table 2. The first layer external environment evaluation decision table.

\begin{tabular}{ccccccccccccccc}
\hline$U$ & $E_{11}$ & $E_{12}$ & $E_{13}$ & $E S$ & $U$ & $E_{11}$ & $E_{12}$ & $E_{13}$ & $E S$ & $U$ & $E_{11}$ & $E_{12}$ & $E_{13}$ & $E S$ \\
\hline 1 & 1 & 1 & 1 & 1 & 10 & 3 & 1 & 1 & 1 & 19 & 5 & 1 & 1 & 3 \\
2 & 1 & 1 & 3 & 1 & 11 & 3 & 1 & 3 & 3 & 20 & 5 & 1 & 3 & 3 \\
3 & 1 & 1 & 5 & 3 & 12 & 3 & 1 & 5 & 3 & 21 & 5 & 1 & 5 & 5 \\
4 & 1 & 3 & 1 & 1 & 13 & 3 & 3 & 1 & 1 & 22 & 5 & 3 & 1 & 3 \\
5 & 1 & 3 & 3 & 3 & 14 & 3 & 3 & 3 & 3 & 23 & 5 & 3 & 3 & 5 \\
6 & 1 & 3 & 5 & 3 & 15 & 3 & 3 & 5 & 3 & 24 & 5 & 3 & 5 & 5 \\
7 & 1 & 5 & 1 & 3 & 16 & 3 & 5 & 1 & 3 & 25 & 5 & 5 & 1 & 3 \\
8 & 1 & 5 & 3 & 3 & 17 & 3 & 5 & 3 & 3 & 26 & 5 & 5 & 3 & 5 \\
9 & 1 & 5 & 5 & 3 & 18 & 3 & 5 & 5 & 3 & 27 & 5 & 5 & 5 & 5 \\
\hline
\end{tabular}

Table 3. The second layer external environment evaluation decision table.

\begin{tabular}{ccccccccccccccc}
\hline$U$ & $E_{21}$ & $E_{22}$ & $E_{23}$ & $E S$ & $U$ & $E_{21}$ & $E_{22}$ & $E_{23}$ & $E S$ & $U$ & $E_{21}$ & $E_{22}$ & $E_{23}$ & $E \mathrm{~S}$ \\
\hline 1 & 1 & 1 & 1 & 1 & 10 & 3 & 1 & 1 & 1 & 19 & 5 & 1 & 1 & 3 \\
2 & 1 & 1 & 3 & 1 & 11 & 3 & 1 & 3 & 1 & 20 & 5 & 1 & 3 & 3 \\
3 & 1 & 1 & 5 & 1 & 12 & 3 & 1 & 5 & 1 & 21 & 5 & 1 & 5 & 3 \\
4 & 1 & 3 & 1 & 1 & 13 & 3 & 3 & 1 & 3 & 22 & 5 & 3 & 1 & 5 \\
5 & 1 & 3 & 3 & 1 & 14 & 3 & 3 & 3 & 3 & 23 & 5 & 3 & 3 & 5 \\
6 & 1 & 3 & 5 & 3 & 15 & 3 & 3 & 5 & 3 & 24 & 5 & 3 & 5 & 5 \\
7 & 1 & 5 & 1 & 3 & 16 & 3 & 5 & 1 & 3 & 25 & 5 & 5 & 1 & 5 \\
8 & 1 & 5 & 3 & 3 & 17 & 3 & 5 & 3 & 3 & 26 & 5 & 5 & 3 & 5 \\
1 & 1 & 1 & 1 & 1 & 10 & 3 & 1 & 1 & 1 & 19 & 5 & 5 & 5 & 5 \\
\hline
\end{tabular}

Table 4. The environment index evaluation calculated results of first layer.

\begin{tabular}{ccccccc}
\hline Evaluation index & $e_{11}$ & $e_{12}$ & $e_{13}$ & $e_{21}$ & $e_{22}$ & $e_{23}$ \\
\hline 0.312 & 0.196 & 0.265 & 0.436 & 0.389 & 0.185
\end{tabular}

more important, very important $\}$, Let the set of evaluation is $v=\left\{v_{1}, v_{2}, v_{3}, v_{4}, v_{5}\right\}$, Value of each weight is:

$v_{1}=1, v_{2}=3, v_{3}=5, v_{4}=7, v_{5}=9$, Corresponding set of evaluation is $v=\{$ bed, worse, general, better, good . The final results of the evaluation of environmental indicators for the first layer is

$$
\begin{aligned}
v=\sum_{i=1}^{5} \sum_{j=1}^{5} m_{i} \lambda_{j}^{\prime}=0.312 \times 2+0.196 \times 3+0.265 \times 4 \\
+0.436 \times 3+0.389 \times 3+0.185 \times 4=5.487
\end{aligned}
$$

The calculatedion only for the first layer with the Enterprise evaluation index system of green technology innovation, but the second layer is similar to the calculation results of the evaluation. The end result in the second layer is equal to the second level evaluation of the environmental factors to be calculated with a layer of environmental factors corresponding to the calculated value of the product. The final results of the evaluation index are shown in Table 5.

By the formula (5), the evaluation range of environmental factors results is $\lambda \in[0,1]$. The better the enviromental factors the greater $\lambda$ 's value, on the contrary, $\lambda$ 's value is smaller, the worse the environmental factors. As can be seen from Table 4, the enterprise whether internal or external environment, there are many areas that need improvement. For example, the external environment should strive for better financial support policies. In the internal environment, although the management of enterprises to implement green technology innovation to give a high degree of attention, but the funding for green technology innovation inputs to be further improved. Meanwhile, enterprises should also strengthen the research and development with the external environment and improve the level of equipment and process improvements.

\section{Conclusions}

The article establishes the business green technology innovation with the internal and external environment indicators, and establishes a rough set theory based on evaluation model. By the above theories, this paper can get the following conclusions and inspiration.

The enterprise evaluation index system of green technology innovation which is established by the paper involves with various aspects of the business internal and

Table 5. The evaluation calculation results of enterprise green technology innovation environment index.

\begin{tabular}{cccccccccc}
\hline \multirow{2}{*}{ External } & $e_{111}$ & $e_{112}$ & $e_{113}$ & $e_{121}$ & $e_{122}$ & $e_{123}$ & $e_{131}$ & $e_{132}$ & $e_{133}$ \\
& 0.279 & 0.268 & 0.582 & 0.159 & 0.175 & 0.165 & 0.245 & 0.296 & 0.257 \\
& $e_{211}$ & $e_{212}$ & $e_{213}$ & $e_{221}$ & $e_{222}$ & $e_{223}$ & $e_{231}$ & $e_{232}$ & $e_{233}$ \\
Internal & 0.417 & 0.569 & 0.586 & 0.551 & 0.462 & 0.205 & 0.265 & 0.125 & 0.262 \\
\hline
\end{tabular}


external environment, it can provide a good environment theoretical basis in the implementation process of green technology innovation. However, the establishment of the enterprise evaluation index system of green technology innovation is a complex system which needs to continue to practice and improve.

The evaluation model which is based on the rough set theory overcomes the traditional rough set model cumbersome bottleneck. At the same time, the model does not require any other prior knowledge, evaluation result depends entirely on the results of the survey, so the environment evaluation of green technology innovation is more objective. The empirical studies show that the established evaluation model has good operability and effectiveness.

Good enterprise environment has a profound impact and role in promoting the green technology innovation. In turn, the successful green technological innovation can contribute to the healthy development of the enterprise environment. The green technology innovation and business environment should be compatible and harmonious development.

\section{Acknowledgements}

This research was supported in part by the project of Tech-innovation Methods Integration Research and Generalizing Application (NO. 2007FY140400) and the Project Supported by Sichuan Circulation Economic Research Center (NO xhjj-1013).

\section{REFERENCES}

[1] Z. R. Hu, “Green Tech Innovation and Enterprise’s Sustainable Development," Technological Development of Enterprise, Vol. 25, No. 11, 2006, pp. 92-94.

[2] V. Norberg and B. Stimulating, "Green Technological Innovation: An Analysis of Alternative Policy Mechanisms," Policy Sciences, Vol. 32, No. 1, 1999, pp. 15-58.

[3] Y. S. Chen, "The Influence of Green Innovation Performance on Corporate Advantage in Taiwan,” Journal of
Business Ethics, Vol. 67, No. 4, 2006, pp. 551-559. doi:10.1007/s10551-006-9025-5

[4] S. C. Yu, "Driver of Green Innovation and Green Image -Green Core Competence,” Journal of Business Ethics, Vol. 81, No. 3, 2008, pp. 531-543. doi:10.1007/s10551-007-9522-1

[5] P. Li, "Technology Innovation from Traditional to Green," Social Sciences Shanghai China, Vol. 6, No. 12, 2011, pp. 11-14.

[6] Y. Ling, “Theory of Green Technology Innovation,” Science \& Technology Progress and Policy, Vol. 17, No. 9, 2000, pp. 64-65.

[7] H. F. Yang, "Green Technology Innovation: Enterprise Development of Circular Economy Effective Power," Seeker, Vol. 5, No. 9, 2005, pp. 35-36.

[8] J. JIAO and Y. Li, "Firm's Green Strategic Orientation and Green Innovation Based on Alliance," $R \& D M a-$ nagement, Vol. 23, No. 1, 2011, pp. 84-89.

[9] Q. H. Zhu and Q. Liu, “Green Innovation among Telecommunication Equipment Manufacturers-An Empirical Study on the Eco-Design Drive Model,” $R \& D$ Management, Vol. 25, No. 1, 2011, pp. 76-83.

[10] Y. Y. Zhu, Z. Q. Ma and Y. Q. Chen, “Multi-Level Fuzzy Comprehensive Evaluation on Enterprise's Green Technology Innovation Environment," Science \& Technology Progress and Policy, Vol. 27, No. 9, 2010, pp. 102-105.

[11] Z. Pawlak, "Rough Set," Communications of the ACM, Vol. 38, No. 11, 1995, pp. 89-95.

[12] T. L. Satty, "The Analytical Hierarchy Process,” McGraw-Hill, New York, 1980.

[13] L Zadeh, "Fuzzy Sets as a Basis for a Theory of Possibility,” Fuzzy Sets and Systems, Vol. 1, No. 1, 1978, pp. 328.

[14] A. P. Dempster, "Upper and Lower Probabilities Induced by a Multivalued Mapping," The Annals of Mathematical Statistics, Vol. 38, No. 2, 1967, pp. 325-339. doi:10.1214/aoms/1177698950

[15] P. Zhao and H. W. Su, "Evaluation of Technical Innovation Environment in Chinese Enterprises," Technology and Innovation Management, Vol. 29, No. 2, 2008, pp. $116-120$ 